\title{
Once-monthly paliperidone injection for the treatment of schizophrenia
}

This article was published in the following Dove Press journal:

Neuropsychiatric Disease and Treatment

30 August 2010

Number of times this article has been viewed

\section{Delia Bishara}

Pharmacy Department, South London and Maudsley NHS Foundation Trust, London, United Kingdom
Correspondence: Delia Bishara Pharmacy Department, South London and Maudsley NHS Foundation Trust, Denmark Hill, London, SE5 8AZ, UK Tel +442032285044

Fax +44 2032285279

Email delia.bishara@slam.nhs.uk
Abstract: Paliperidone palmitate is a new long-acting antipsychotic injection for the treatment of acute and maintenance therapy in schizophrenia. Paliperidone (9-hydroxyrisperidone) is the major active metabolite of risperidone and acts at dopamine $\mathrm{D}_{2}$ and serotonin $5 \mathrm{HT}_{2 \mathrm{~A}}$ receptors. As with other atypical antipsychotics, it exhibits a high $5 \mathrm{HT}_{2 \mathrm{~A}}: \mathrm{D}_{2}$ affinity ratio. It also has binding activity as an antagonist at $\alpha_{1}$ - and $\alpha_{2}$ adrenergic receptors and $H_{1}$ histaminergic receptors, but has virtually no affinity for cholinergic receptors. Paliperidone palmitate has been shown to be effective in reducing Positive and Negative Syndrome Scale total scores in four short-term trials in acute schizophrenia. It was also effective as maintenance therapy in a long-term trial in which time to recurrence of symptoms was significantly longer in paliperidone-treated patients compared with placebo. In addition, paliperidone was shown to be noninferior to risperidone long-acting injection in one study, but this noninferiority was not established in another longer study comparing the two drugs. Treatment should be initiated with $234 \mathrm{mg}$ on day 1 and $156 \mathrm{mg}$ on day 8 , followed by a recommended monthly maintenance dose of 39-234 mg based on efficacy and tolerability. Paliperidone palmitate is generally well tolerated, although it can cause weight gain and a rise in prolactin levels, which is generally greater in women than in men. Overall, paliperidone palmitate may have advantages over other currently available long-acting injections, and therefore may be a useful alternative for the treatment of schizophrenia, although further long-term trials comparing it with active treatments are warranted.

Keywords: paliperidone palmitate, injection, schizophrenia, long-acting

\section{Introduction}

Poor compliance with medication remains a major cause for concern in the management of schizophrenia. It has been shown that more than $35 \%$ of patients experience compliance problems within the first few weeks of therapy, and only $25 \%$ are fully compliant after two years. ${ }^{1}$ A combination of factors may contribute to this problem, including lack of insight, negative symptoms, cognitive decline, and poor tolerability of available agents. These have a major negative impact on compliance which, in turn, leads to considerable risk of relapse, thus reducing the likelihood of full recovery to the baseline level of functioning. ${ }^{1}$

Conventional antipsychotic depot formulations were first introduced in the $1960 \mathrm{~s}$ as a means to improve compliance with therapy. However, the negative symptoms of schizophrenia are not adequately managed by these older drugs, and their high propensity to cause extrapyramidal symptoms and raised prolactin levels has limited their use over time. Of late, after many years of research and development, pharmaceutical companies have also succeeded in formulating certain atypical antipsychotics 
into long-acting injections. Risperidone was the first atypical agent to be formulated as a long-acting injection, administered every two weeks. However, supplementary oral treatment is required for the first 4-6 weeks of intramuscular therapy due to the delay in reaching steady-state plasma levels. In addition, although the three licensed doses $(25 \mathrm{mg}$, $37.5 \mathrm{mg}$, and $50 \mathrm{mg}$ every two weeks) have been shown to be equally effective in clinical trials, the lowest dose $(25 \mathrm{mg}$ every two weeks) has been shown to be relatively less effective in practice. ${ }^{2}$

Olanzapine has also been recently formulated into a pamoate suspension for intramuscular administration every 2-4 weeks. With this product, a safety risk emerged during clinical trials known as "post-injection syndrome", consisting of an unexpected high degree of sedation, confusion, dizziness, altered speech, and/or unconsciousness occurring in a small number of patients following injection. ${ }^{3}$ The incidence of this has been estimated as $1.2 \%$ of patients treated, or $0.07 \%$ of injections given. ${ }^{4}$ The formulation went on to gain its license despite this adverse effect, but with the recommendation that a three-hour patient observation period follow each injection, a restriction that will most likely limit its use for practical reasons, as well as the safety issues involved. ${ }^{4}$

While the introduction of atypical antipsychotic drugs has been of some benefit to patients, the use of these new agents has been accompanied by serious adverse effects also limiting their clinical use. Atypical antipsychotics have been implicated in the development of metabolic disorder, ${ }^{5}$ consisting of raised cholesterol and triglycerides alongside impaired glucose tolerance. ${ }^{6}$ The likelihood of experiencing these adverse effects varies amongst the different drugs in this class. Furthermore, considerable weight gain ${ }^{7}$ is an additional risk, often leading to early treatment discontinuation and poor compliance with therapy. As a result, despite the increasing number of agents being developed for the management of schizophrenia, there are still many individuals who are not receiving adequate benefit or not able to tolerate currently available agents. The introduction of paliperidone oncemonthly injections is therefore a welcome addition to the market. In this paper, the pharmacology, pharmacokinetics, efficacy, and safety of paliperidone palmitate are reviewed, and its potential place in the treatment of schizophrenia is discussed.

\section{Paliperidone palmitate}

Paliperidone palmitate is the most recent atypical antipsychotic to be developed as a long-acting injection and was approved by the US Food and Drug Administration in August 2009 for acute and maintenance therapy in adult patients with schizophrenia. A marketing authorization application has been submitted to the European Medicines Agency, whereby following approval, it will be marketed in Europe, and marketing applications in other areas of the world are ongoing.

\section{Pharmacology}

Paliperidone, also described as 9-hydroxyrisperidone, is the major active metabolite of risperidone. Its pharmacology and mechanism of action are therefore believed to be similar to that of risperidone. Paliperidone acts as an antagonist at dopamine $\mathrm{D}_{2}$ and serotonin $5 \mathrm{HT}_{2 \mathrm{~A}}$ receptors, exhibiting a high $5 \mathrm{HT}_{2 \mathrm{~A}}: \mathrm{D}_{2}$ affinity ratio, as with other atypical agents. ${ }^{8}$ It also has binding activity as an antagonist at $\alpha_{1}$ - and $\alpha_{2}$-adrenergic receptors and $\mathrm{H}_{1}$-histaminergic receptors, but has virtually no affinity for cholinergic receptors. ${ }^{8-10}$ Paliperidone's activity profile suggests that it has the potential to cause orthostatic hypotension, weight gain, and sedation. However, because it has no antagonistic activity at cholinergic receptors, it has a low propensity to cause anticholinergic adverse effects and cognitive impairment.

\section{Pharmacokinetics}

Paliperidone palmitate is a benzisoxazole derivative which is hydrolyzed to the active moiety, paliperidone, and absorbed into the systemic circulation (see Figure 1). The palmitate ester of paliperidone is an aqueous suspension which utilizes nanoparticle technology. The resulting increased surface area leads to rapid release of medication and therefore a relatively short time to steady state. Following an injection, active paliperidone plasma levels have been detected from day 1 , therefore coadministration with oral paliperidone on initiation of therapy is not required. Following the intramuscular administration of single doses in the deltoid muscle, on average a $28 \%$ higher peak concentration is observed compared with injection in the gluteal muscle. However, after four injections, there is no difference between the time to maximum plasma concentration and area under the curve between the two injection sites. ${ }^{11,12}$ Thus, the two initial deltoid muscle injections on days 1 and 8 (see Table 1) help to attain therapeutic drug concentrations rapidly. ${ }^{13}$

Paliperidone is largely excreted unchanged in the urine. Four metabolic pathways have been identified for the metabolism of paliperidone including dealkylation, hydroxylation, dehydrogenation, and benzisoxazole scission, although none accounted for more than $10 \%$ of the oral dose administered. ${ }^{13}$ 

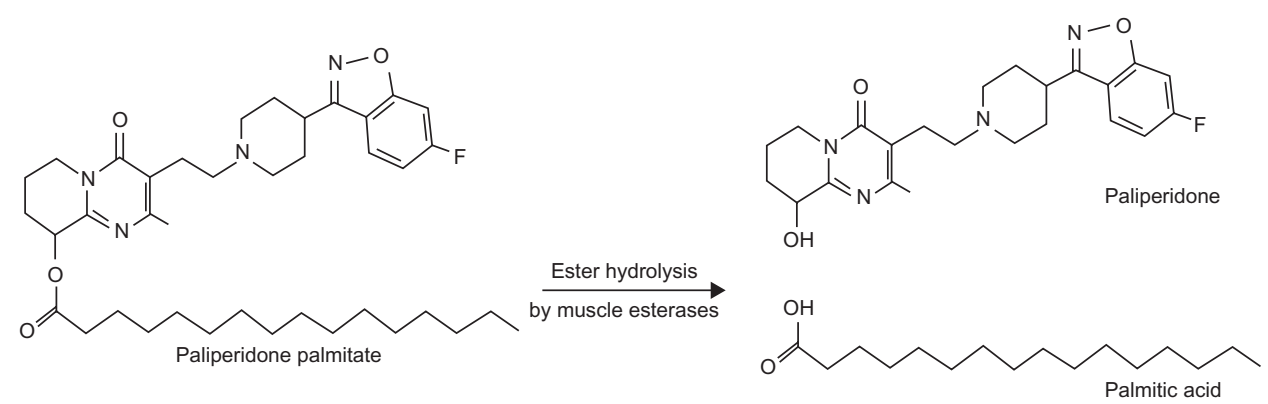

Figure I Formation of paliperidone from paliperidone palmitate.

While cytochrome P450 (CYP) 2D6 and CYP3A4 have been implicated in the metabolism of paliperidone in in vitro studies, these isoenzymes play a limited role in the metabolism of paliperidone in vivo. The nanocrystal molecules which make up the paliperidone palmitate suspension also allow it to undergo slow dissolution, yielding a half-life of 25-49 days (see Table 2). ${ }^{13-16}$ The relatively long half-life allows for the monthly administration of paliperidone intramuscular injections.

\section{Efficacy in schizophrenia Efficacy in clinical trials}

The therapeutic efficacy of paliperidone palmitate oncemonthly injection has been evaluated in four short-term (nine- and 13-week) multicenter, randomized, double-blind, placebo-controlled trials in acute schizophrenia. ${ }^{14,17-19}$ In all four trials, the injection was administered on days 1,8 , and 36 and, in the 13-week trials, also on day 64. Paliperidone palmitate's efficacy as maintenance therapy in schizophrenia has also been evaluated in a 52-week recurrence prevention

Table I Paliperidone palmitate injection dose and administration information $^{13}$

\begin{tabular}{|c|c|c|}
\hline Initiation & Dose & Administration route \\
\hline Day I & $234 \mathrm{mg}$ & Deltoid muscle only \\
\hline Day 8 ( \pm 2 days) & $156 \mathrm{mg}$ & Deltoid muscle only \\
\hline \multicolumn{3}{|l|}{ Maintenance } \\
\hline $\begin{array}{l}\text { From Day } 36 \text { every } \\
\text { four weeks ( } \pm 7 \text { days) }\end{array}$ & $39-234 \mathrm{mg}$ & $\begin{array}{l}\text { Either gluteal or deltoid } \\
\text { muscle }\end{array}$ \\
\hline \multicolumn{3}{|c|}{ Equivalent paliperidone dosages } \\
\hline Oral (mg/day) & \multicolumn{2}{|c|}{ Intramuscular (every four weeks) } \\
\hline 2 & \multicolumn{2}{|c|}{39 mg (25 mg eq) } \\
\hline 4 & \multicolumn{2}{|c|}{78 mg (50 mg eq) } \\
\hline 6 & \multicolumn{2}{|c|}{ II 7 mg (75 mg eq) } \\
\hline 9 & \multicolumn{2}{|c|}{ I56 mg (100 mg eq) } \\
\hline 12 & \multicolumn{2}{|c|}{234 mg (I 50 mg eq) } \\
\hline
\end{tabular}

Notes: Although commercially available product dosage strengths of paliperidone palmitate are labeled in milligrams ( $\mathrm{mg}$ ) of paliperidone, all current published poster presentations and clinical trials have doses reported as milligram equivalents ( $\mathrm{mg}$ eq) of paliperidone.

Abbreviation: $\mathrm{mg}$ eq, milligram equivalents. study ${ }^{20}$ and a further 52-week, open-label extension phase of this study. ${ }^{21}$ In addition, two studies compared its clinical efficacy with intramuscular long-acting risperidone injection. ${ }^{22,23}$ Many of these studies are currently only available as poster presentations. The main efficacy findings from the trials are summarized below (and also in Table 3 ).

\section{Acute efficacy}

The primary efficacy endpoint in all studies was the mean change in Positive and Negative Syndrome Scale (PANSS) total score ${ }^{24}$ from baseline to endpoint. Secondary endpoints included changes in Clinical Global Impression of Severity (CGI-S), ${ }^{25}$ PANSS factor and subscale scores, and Personal and Social Performance Scale (PSP). ${ }^{26}$

In the largest dose-response study, intramuscular paliperidone was effective in the treatment of adult patients with acute schizophrenia, producing significant $(P \leq 0.034)$ and dose-related changes in PANSS total score from baseline for each of the three paliperidone groups $(39,156$, and $234 \mathrm{mg}$ ) compared with placebo. ${ }^{18}$ A significant change in PANSS total score was observed as early as day 8 for paliperidone 39 and $234 \mathrm{mg}$ and from day 22 for paliperidone $156 \mathrm{mg}$, and was maintained until the endpoint. Significantly more

Table 2 Pharmacokinetic properties of paliperidone palmitate ${ }^{13-16}$

\begin{tabular}{ll}
\hline $\begin{array}{l}\text { Median time to maximum } \\
\text { plasma concentration } \\
\begin{array}{l}\text { Plasma protein binding } \\
\text { (racemic paliperidone) }\end{array}\end{array}$ & $74 \%$ \\
$\begin{array}{l}\text { Mean apparent volume } \\
\text { of distribution }\end{array}$ & 39 I L \\
$\begin{array}{l}\text { Median apparent half-life } \\
\text { (after single-dose administration) }\end{array}$ & $25-49$ days \\
$\begin{array}{l}\text { Metabolism } \\
\text { Minimal metabolism occurs in the }\end{array}$ & $\begin{array}{l}\text { liver (dose adjustment needed } \\
\text { only in severe hepatic impairment) } \\
\text { Up to 60\% excreted unchanged by } \\
\text { kidneys (lower doses needed } \\
\text { in renal impairment) }\end{array}$ \\
\hline
\end{tabular}




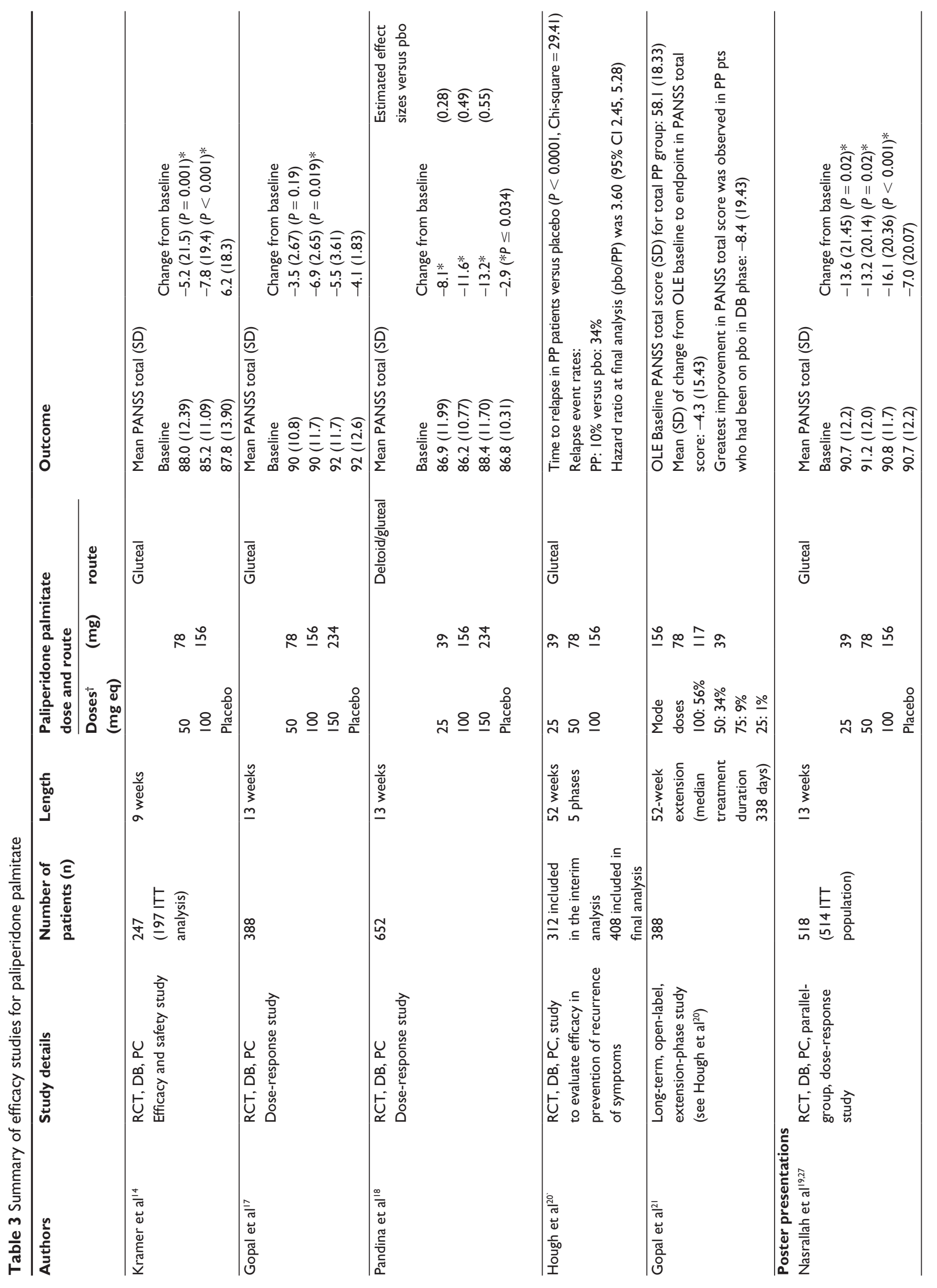




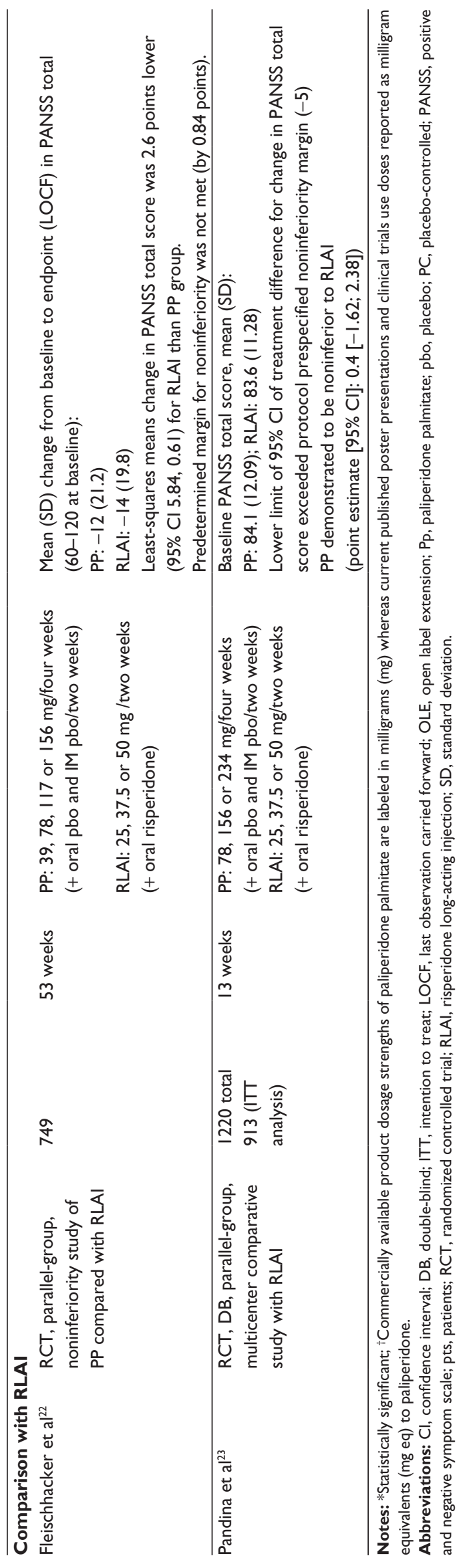

patients on paliperidone responded to treatment $(39 \mathrm{mg}$ $33.5 \%, P=0.007 ; 156 \mathrm{mg} 41.0 \%, P<0.001 ; 234 \mathrm{mg} 40.0 \%$, $P<0.001)$ compared with placebo $(20.0 \%) .{ }^{18}$

These findings are supported by two smaller, published, dose-response studies..$^{14,17}$ In the first study, both doses of paliperidone (78 $\mathrm{mg}$ and $156 \mathrm{mg}$ ) produced significant $(P \leq 0.001)$ mean changes from baseline in PANSS total score (-5.2 [21.5)] and -7.8 [19.4], respectively) compared with placebo (6.2 [18.3]). ${ }^{14}$ In the second study, significant changes in PANSS total score compared with placebo were noted with the $156 \mathrm{mg}$ dose $(P=0.019)$ but not with the $78 \mathrm{mg}$ dose $(P=0.19) .{ }^{17}$ No statistical comparison was performed for the $234 \mathrm{mg}$ treatment group, therefore a dose-response relationship could not be ascertained from this study.

\section{Long-term efficacy}

There has also been a long-term maintenance study of recurrence prevention using paliperidone palmitate, which consisted of five phases, including a seven-day screening, washout, and tolerability period, a nine-week, open-label transition phase during which intramuscular paliperidone was initiated, a 24-week, open-label, maintenance phase with flexible dosing until week 21 , a randomized, doubleblind, placebo-controlled phase of variable duration, ${ }^{20}$ and an optional 52-week, open-label extension phase. ${ }^{21} \mathrm{~A}$ recurrence event was defined as time to the first emergence of one or more of the following: hospitalization (for symptoms of schizophrenia), prespecified changes in PANSS scores or clinically significant deliberate self-injury or aggressive behavior. The primary outcome measure was time from randomization to the first recurrent event. A preplanned interim analysis was carried out in order to minimize the number of patients exposed to placebo. In the interim analysis (planned after 68 relapse events) paliperidone palmitate was superior to placebo, with recurrence of events seen in $15(10 \%)$ patients in the paliperidone group compared with 53 (34\%) patients in the placebo group, ${ }^{20}$ yielding a numbers needed to treat of five $\left(95 \%\right.$ confidence interval [CI] 4-7). ${ }^{27}$

In the open-label extension phase of this study, improvements from baseline to the endpoint were observed on PANSS, PSP, and CGI-S assessment. ${ }^{21}$ Overall improvements in PANSS total scores observed during the previous study phases were maintained during the open-label phase for patients treated with paliperidone (mean $\pm \mathrm{SD}$ of the change in PANSS total score $-4.3 \pm 15.43$ ). The greatest improvement in PANSS total score occurred in patients who were treated with placebo in the double-blind phase $(-8.4 \pm 19.43)$. Functional improvement as measured by 
the PSP scale, also continued during the open-label phase, with the greatest improvement observed in patients previously on placebo in the double-blind phase (change in PSP score $6.0 \pm 13.20$ ). The authors reported that the majority of patients stayed in this open-label phase for one year, and demonstrated maintenance of symptoms as well as functional improvements.

\section{Efficacy compared with active comparator}

Paliperidone palmitate injection was compared with risperidone long-acting injection (RLAI) in a 53-week noninferiority study. ${ }^{22}$ Patients were randomized (1:1) to receive double-blind flexible doses of paliperidone 39-156 mg every four weeks by gluteal injection (after two initiation doses of $78 \mathrm{mg}$ on days 1 and 8) or RLAI 25, 37.5, or $50 \mathrm{mg}$ every two weeks. Oral supplementation with risperidone was provided to the RLAI patients (as well as a placebo injection on day 1), and matched paliperidone patients received oral placebo and two-weekly placebo injections to coincide with RLAI frequency.

Although both agents resulted in decreases in PANSS total score $(-12 \pm 21.2$ for paliperidone and $-14 \pm 19.8$ for RLAI), paliperidone was not shown to be noninferior to RLAI, based on the predetermined margin of 5 points. Least-squares means change in PANSS total score was 2.6 points lower $(95 \%$ CI $-5.84,0.61)$ for RLAI compared with paliperidone. As such, the predetermined margin for noninferiority (lower limit of the $95 \%$ CI should be greater than -5 points) was not met (by 0.84 points). However, the authors concluded that noninferiority was not established because patients had been initiated with suboptimal initial dosing of paliperidone, substantially lower than the initiation doses currently recommended in the product labeling. Therefore, this may have resulted in lower plasma concentrations until day 260 compared with those in the RLAI group. In addition, the authors believed that utilization of the gluteal initiation site may have also led to lower plasma levels of paliperidone, because this site of administration is associated with lower initial exposure.

Consequently, another noninferiority study between paliperidone palmitate and RLAI was performed, acknowledging the optimized initiation dosing regimen for paliperidone. ${ }^{23}$ This was a randomized (1:1), double-blind, double-dummy, active-controlled, parallel-group, 13-week comparative Phase III study. Paliperidone deltoid injections of $234 \mathrm{mg}$ on day 1 and $156 \mathrm{mg}$ on day 8 were given, followed by once-monthly flexible dosing (78-234 mg) as either deltoid or gluteal injections (and placebo injections matched to RLAI). The other group received RLAI starting at $25 \mathrm{mg}$ on day 8 , followed by biweekly injections which could be increased up to $37.5 \mathrm{mg}$ on day 36 and up to $50 \mathrm{mg}$ on day 64 (and placebo injections matched to the paliperidone initiation regimen). Patients on RLAI received oral risperidone supplementation (1-6 mg from days 1-28), while the paliperidone group received a matching oral placebo.

The primary endpoint was the change in PANSS total score from baseline to the double-blind endpoint. Noninferiority of paliperidone compared with RLAI was to be concluded if the lower limit of the two-sided 95\% CI exceeded -5 . Additional secondary endpoints included PANSS subscales, CGI-S, and PSP. Unlike the previous study, the lower limit of the $95 \% \mathrm{CI}$ of the treatment difference for the change in PANSS total score did exceed the prespecified protocol noninferiority margin of -5 , and therefore paliperidone was shown to be noninferior to RLAI (point estimate [95\% CI] $0.4[-1.62 ; 2.38])$. In addition, both groups showed similar improvements in CGI-S and PSP, as well as other secondary measures. ${ }^{23}$ Limitations of this study include its relatively short duration, lasting only 13 weeks compared with 53 weeks in the previous one, and therefore the longer-term efficacy of paliperidone palmitate cannot be compared with RLAI from these findings. Furthermore, doses above $25 \mathrm{mg}$ were not allowed in the RLAI group for several weeks, despite evidence to show that RLAI $25 \mathrm{mg}$ may be ineffective in the majority of patients. ${ }^{2}$ In fact, many patients in clinical practice nowadays are being initiated on $37.5 \mathrm{mg}$ of RLAI, and the higher doses are generally used a lot sooner in the therapeutic regimen.

\section{Safety and tolerability}

The safety and tolerability of paliperidone palmitate were also assessed in the studies already described. The main findings are summarized in this section (and in Table 4). Treatment emergent adverse effects (TEAEs) occurring more frequently in the paliperidone palmitate groups than in the placebo group included insomnia, headache, dizziness, sedation, vomiting, schizophrenia, injection site pain, extremity pain, myalgia, and extrapyramidal symptoms. ${ }^{14,17}$

\section{Safety in acute therapy}

In the nine-week study, parkinsonian-type adverse effects, including drooling and hypertonia, were the most common extrapyramidal side effects, and occurred more frequently in the paliperidone groups than placebo. ${ }^{14}$ Other extrapyramidal side effects occurred similarly in all groups and 
Table 4 Summary of safety studies for paliperidone palmitate

\begin{tabular}{|c|c|c|c|}
\hline Authors & Study details & $\begin{array}{l}\text { Number of } \\
\text { patients (n) }\end{array}$ & Safety outcomes for paliperidone palmitate \\
\hline Kramer et al ${ }^{14}$ & $\begin{array}{l}\text { RCT, DB, PC } \\
\text { Nine-week, efficacy and safety } \\
\text { study }\end{array}$ & 247 & 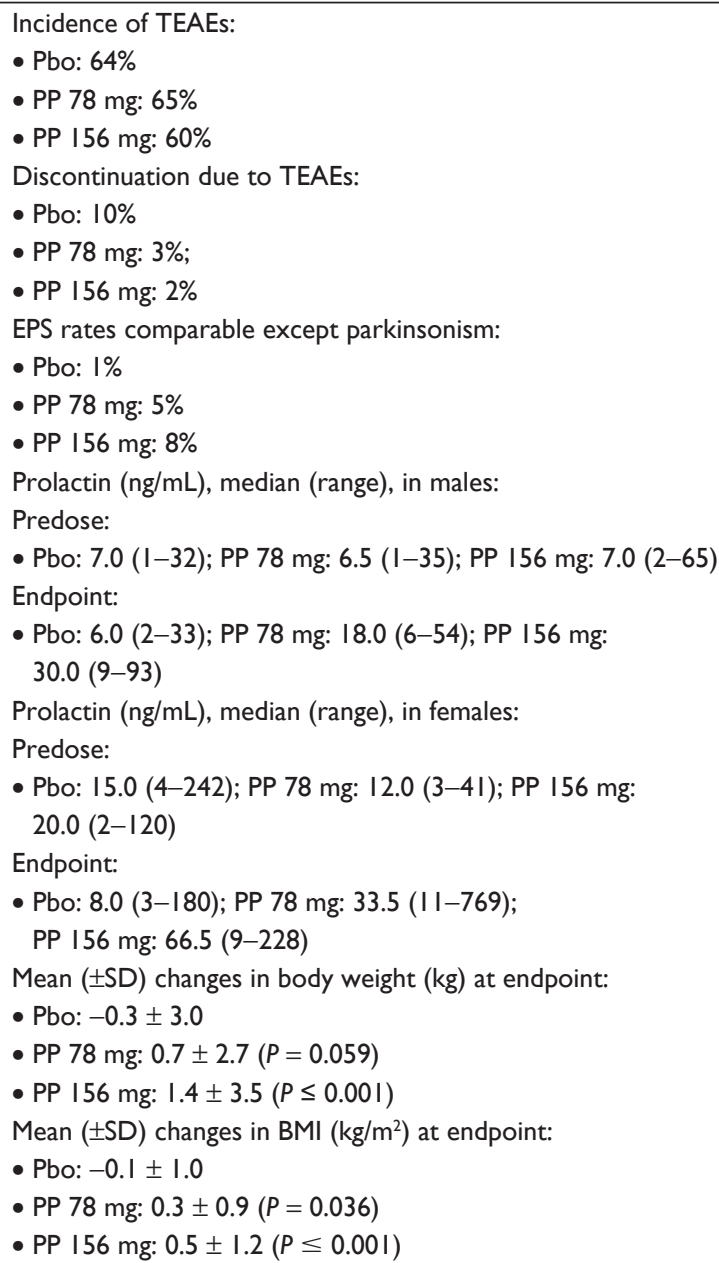 \\
\hline Hough et $\mathrm{a}^{28}$ & $\begin{array}{l}\text { Randomized, } 25 \text {-week, crossover } \\
\text { study comparing deltoid and gluteal } \\
\text { administration of PP } 78,117 \text {, } \\
\text { and } 156 \mathrm{mg}\end{array}$ & $\begin{array}{l}252 \\
\text { (ITT: 249) }\end{array}$ & $\begin{array}{l}\text { Overall incidence of TEAEs: } \\
\text { - Deltoid- period I: } 64 \% \text {, period 2: } 51 \% \\
\text { - Gluteal- period I: } 63 \% \text {, period 2: } 46 \% \\
\text { Incidence of extrapyramidal-related TEAEs: } \\
\text { - Period I: } 7 \% \text { deltoid, } 10 \% \text { gluteal } \\
\text { - Period 2: } 2 \% \text { deltoid, } 6 \% \text { gluteal }\end{array}$ \\
\hline Gopal et al ${ }^{17}$ & $\begin{array}{l}\text { RCT, DB, PC } \\
\text { I } 3 \text { weeks } \\
\text { Dose-response study }\end{array}$ & 388 & 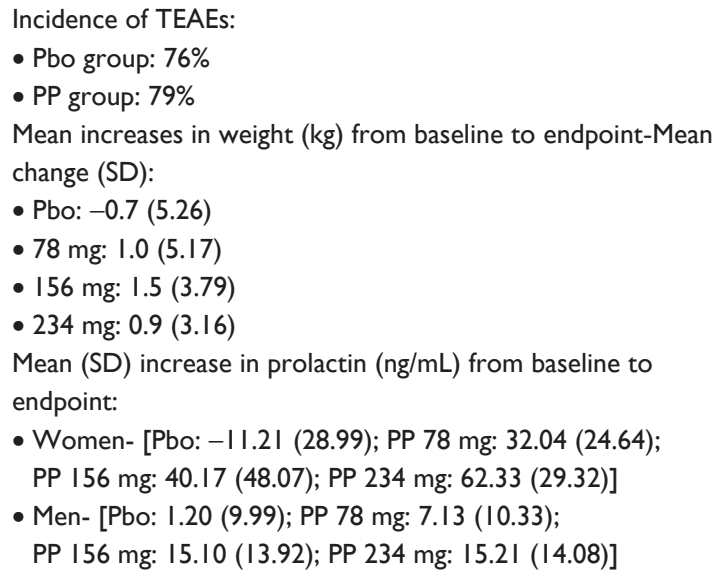 \\
\hline
\end{tabular}


Table 4 (Continued)

\begin{tabular}{|c|c|c|c|}
\hline Authors & Study details & $\begin{array}{l}\text { Number of } \\
\text { patients (n) }\end{array}$ & Safety outcomes for paliperidone palmitate \\
\hline Pandina et al $^{18}$ & $\begin{array}{l}\mathrm{RCT}, \mathrm{DB}, \mathrm{PC} \mathrm{I} 3 \text { weeks } \\
\text { Dose-response study }\end{array}$ & 652 & $\begin{array}{l}\text { Similar TEAE rates: } \\
\text { - Pbo group: } 65 \% \\
\text { - PP group: } 60-63 \% \\
\text { Weight increase of ( } \geq 7 \% \text { ) occurred in: } \\
\text { - Pbo: } 5 \% \\
\text { - PP: } 39 \mathrm{mg}: 6 \% \\
\text { - PP: } 156 \mathrm{mg}: 8 \% \\
\text { - PP: } 234 \mathrm{mg}: 13 \% \\
\text { Mean increase in prolactin levels from baseline: } \\
\text { PP groups } \\
\text { - Women: } 4.72-37.24 \mathrm{ng} / \mathrm{mL} \\
\text { - Men: } 3.73-13.15 \mathrm{ng} / \mathrm{mL} \\
\text { Pbo: prolactin levels decreased in both sexes }\end{array}$ \\
\hline Hough et $\mathrm{al}^{20}$ & $\begin{array}{l}\text { RCT, DB, PC } \\
52 \text {-week study to evaluate efficacy } \\
\text { in prevention of recurrence of } \\
\text { symptoms }\end{array}$ & 408 & $\begin{array}{l}\text { Abnormal weight increase }(\geq 7 \%) \text { : } \\
\text { - PP: } 23 \% \text { versus pbo: I } 2 \% \text { from transition baseline to endpoint } \\
\text { - PP: } 6 \% \text { versus pbo: } 3 \% \text { from DB baseline to endpoint } \\
\text { Mean weight increased by } 1.9 \mathrm{~kg} \text { in PP group but remained } \\
\text { unchanged in pbo group } \\
\text { Blood glucose increase ( } \geq 2 \% \text { difference): } \\
\text { - PP: } 3 \% \text { versus pbo: } 1 \% \\
\text { Mean (SD) increase in prolactin ( } \mathrm{ng} / \mathrm{mL}) \text { during DB phase: } \\
\text { - Women- PP: I2.7 (28.64) versus pbo: }-16.6(28.70) \\
\text { - Men- PP: } 3.7(15.70) \text { versus pbo: }-9.2(12.36)\end{array}$ \\
\hline Gopal et $\mathrm{al}^{21}$ & $\begin{array}{l}\text { Open-label, extension-phase } \\
\left(\text { see Hough et } \mathrm{al}^{20} \text { ) }\right.\end{array}$ & 388 & $\begin{array}{l}\text { Weight change for total PP group: } 0.9 \pm 4.26 \mathrm{~kg} \\
\text { I } 3 \% \text { of patients experienced } \geq 7 \% \text { weight increase at endpoint. } \\
\text { Prolactin levels increased in patients on PP who were on pbo in } \\
\text { previous phase (pbo/PP) compared with those on } \\
\text { PP in previous phase (PP/PP): } \\
\text { - Mean increase in pbo/PP group: } 7.16 \mathrm{ng} / \mathrm{mL} \text { (male); } \\
17 \mathrm{ng} / \mathrm{mL} \text { (female) } \\
\text { - Mean changes in PP/PP group: }-2.59 \mathrm{ng} / \mathrm{mL} \text { (male); } \\
-3.07 \mathrm{ng} / \mathrm{mL} \text { (female) }\end{array}$ \\
\hline \multicolumn{4}{|c|}{ Poster presentations } \\
\hline Nasrallah et al ${ }^{19}$ & $\begin{array}{l}\mathrm{RCT}, \mathrm{DB}, \mathrm{PC} \\
\text { I3-week, parallel-group, } \\
\text { dose-response study }\end{array}$ & 514 & 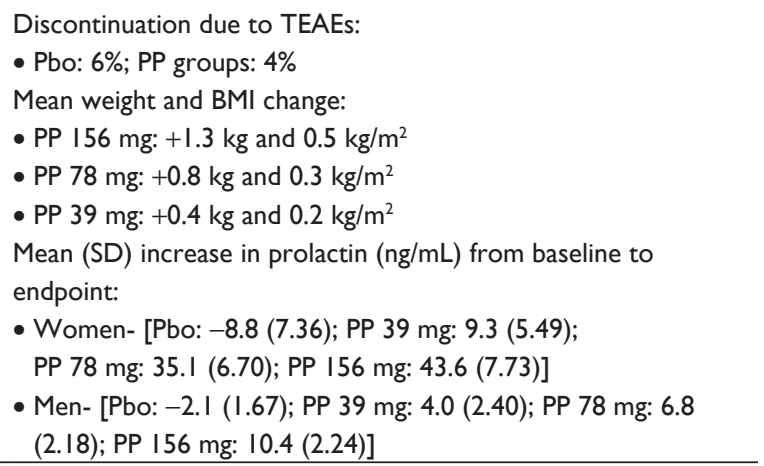 \\
\hline Coppola et $\mathrm{al}^{29}$ & $\begin{array}{l}\text { One-year, open-label } \\
\text { study evaluating long-term } \\
\text { safety, tolerability, and } \\
\text { pharmacokinetics of PP } 234 \mathrm{mg} \\
\text { monthly }\end{array}$ & 212 & $\begin{array}{l}\text { A total of I } 84 \text { pts ( } 87 \% \text { ) experienced } \geq I \text { TEAE. } \\
27 \text { pts (I3\%) discontinued due to TEAEs. } \\
\text { I I pts (5\%) discontinued due to serious TEAEs. } \\
\text { No deaths were reported during the study. } \\
\text { The most frequent TEAEs (in } \geq 5 \% \text { patients) were: } \\
\text { - Nasopharyngitis, insomnia, injection-site pain, headache, tachycardia } \\
\text { Incidence of EPS occurred in } 50 \text { patients ( } 23.6 \%) \\
\text { Overall body weight increases of } \geq 7 \% \text { in } 65 \text { patients ( } 31 \%) \text {. Mean } \\
\text { body weight increased by } 3.9 \% \text { from baseline to endpoint. } \\
\text { Prolactin-related adverse effects in } 4 I \text { patients }(19 \%) \text {. Incidences } \\
\text { were higher in women }(32.8 \%) \text { than men }(\mid 4.3 \%)\end{array}$ \\
\hline
\end{tabular}


Table 4 (Continued)

\begin{tabular}{|c|c|c|c|}
\hline Authors & Study details & $\begin{array}{l}\text { Number of } \\
\text { patients (n) }\end{array}$ & Safety outcomes for paliperidone palmitate \\
\hline \multicolumn{4}{|c|}{ Comparison with RLAI } \\
\hline Fleischhacker et $\mathrm{al}^{22}$ & $\begin{array}{l}\text { RCT, 53-week, parallel-group, } \\
\text { noninferiority study of PP } \\
\text { compared with RLAI }\end{array}$ & $\begin{array}{l}747 \\
\text { (included in } \\
\text { safety analysis) }\end{array}$ & $\begin{array}{l}\text { Rates of TEAEs: } \\
\text { - } 76 \% \text { in PP + pbo group } \\
\text { - } 79 \% \text { in RLAI + oral risperidone } \\
\text { Rates of TEAEs leading to discontinuation } \\
\text { - } 7 \% \text { in PP + pbo group } \\
\text { - } 6 \% \text { in RLAI + oral risperidone group } \\
\text { Rates of serious TEAEs: } \\
\text { - } 29 \% \text { in PP group versus } 21 \% \text { in RLAI group } \\
\text { Incidences of EPS were similar in both groups except } \\
\text { hyperkinesias: } \\
\text { - } 6 \% \text { in PP group versus } 10 \% \text { in RLAI group } \\
\text { Mean (SD) change in body weight from baseline to endpoint: } \\
\text { - PP group: - } 0.2 \mathrm{~kg}(6.0 \mathrm{I}) \text { versus } \\
\text { - RLAI group: } 0.8 \mathrm{~kg}(5.65)\end{array}$ \\
\hline Pandina et $\mathrm{al}^{23}$ & $\begin{array}{l}\text { RCT, DB, parallel-group, } \\
\text { noninferiority study with RLAI } \\
\text { I } 3 \text { weeks }\end{array}$ & $\begin{array}{l}1214 \\
\text { (safety analysis } \\
\text { set) }\end{array}$ & $\begin{array}{l}\text { Rate of TEAEs: } \\
\text { - PP ( } 57.9 \%) \text { versus RLAI }(52.8 \%) \\
\text { Insomnia ( } 9.4 \% \text { versus } 6.7 \%) \text {, injection site pain }(5.1 \% \text { versus } \\
0.8 \%) \text { and anxiety }(4.3 \% \text { versus } 2.1 \%) \text { occurred at } \geq 2 \% \text { higher } \\
\text { incidence in PP group than RLAI. } \\
\text { Incidence of glucose-related TEAEs ( }<\text { I\% patients), EPS, mean } \\
\text { [SD] increases in body weight at endpoint (PP: I.I [3.36] kg, } \\
\text { RLAI: I.0 [3.I4] kg) and injection site tolerability were similar in } \\
\text { both groups. }\end{array}$ \\
\hline
\end{tabular}

Abbreviations: DB, double-blind; ECG, electrocardiogram; EPS, extrapyramidal symptoms; ITT, intention to treat; PP, paliperidone palmitate; pbo, placebo; PC, placebocontrolled; RC, randomized controlled trial; SD, standard deviation; TEAE, treatment emergent adverse effect.

were not considered severe in intensity. Median prolactin levels remained elevated for the paliperidone treatment groups compared with median predose treatment values, whereas prolactin levels decreased to pretreatment values in the placebo patients (see Table 4). The percentage of patients with a $>7 \%$ increase in weight was reported to be $6-8 \%$ of patients in the paliperidone groups versus $4 \%$ for placebo-treated patients. Although the authors considered this weight increase to be low, it was still up to twice that seen in the placebo patients, therefore may be of clinical significance and a potential cause of metabolic complications. In addition, significant mean increases in body weight and body mass index from baseline to endpoint were observed for the $156 \mathrm{mg}$ dose $(P \leq 0.001$ for both measures) and increases for the $78 \mathrm{mg}$ dose compared with placebo were $P=0.036$ for body mass index and $P=0.059$ for weight (see Table 4). The incidence of increased heart rate was higher for paliperidone-treated patients $(17 \%)$ than for placebo $(8 \%)$, as was the incidence of orthostatic hypotension ( $9 \%$ versus $4 \%$, respectively), although none of the latter were reported as adverse effects or symptomatic, and the incidence of tachycardia was low $(<2 \%)$. In addition, although the study was not powered to assess safety, cardiac tolerability appeared to be good, with no patients on paliperidone experiencing $\mathrm{QT}_{\mathrm{c}}$ prolongation or $\mathrm{a} \mathrm{QT}_{\mathrm{c}}>450$ msec during the study. ${ }^{14}$

In the small 13-week trial, the frequency of glucoserelated adverse effects was the same $(2 \%)$ in the placebo and paliperidone groups. ${ }^{17}$ As in the previous study, clinically relevant weight increases ( $>7 \%$ from baseline to endpoint) were more common among patients in the paliperidone groups (78 mg 12\%, $156 \mathrm{mg} \mathrm{10 \% ,} 234 \mathrm{mg} \mathrm{4 \% )} \mathrm{compared} \mathrm{with} \mathrm{pla-}$ cebo $(2 \%)$, although the percentage of people with clinically relevant weight increases did not rise with increasing dose. In addition, mean increases in weight from baseline to endpoint were modest, and ranged from 0.9 to $1.5 \mathrm{~kg}$ but did not appear to be dose-related (see Table 4). However, mean increases in prolactin levels from baseline to endpoint were seen in all paliperidone groups, and increases were larger for the $156 \mathrm{mg}$ and $234 \mathrm{mg}$ groups than for the $78 \mathrm{mg}$ group in both women and men, suggesting a dose-related relationship. There were no clinically relevant changes in vital signs, electrocardiogram (ECG) recordings, or other clinical laboratory parameters, and local injection site tolerability was reported to be good.

In the largest dose-response study, the incidence of TEAEs leading to study discontinuation was similar across 
treatment groups (placebo 6.7\%, paliperidone 6.1\%-8\%). ${ }^{18}$ However, the incidence of serious TEAEs was higher in the placebo group (14\%) than in the paliperidone groups (39 $\mathrm{mg}$

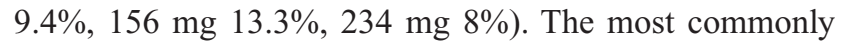
reported serious TEAEs for paliperidone were worsening or exacerbation of schizophrenia (4.9\%) and psychotic disorder $(2.9 \%)$, although these figures were lower than those reported for placebo $(6.1 \%$ and $4.3 \%$, respectively). Unlike the previous study, a weight increase of $7 \%$ or higher was found to occur more frequently with the higher doses of paliperidone (see Table 4). There were no clinically relevant changes from baseline in vital signs, ECG recordings, or other laboratory parameters (including fasting glucose levels and serum lipids) in the paliperidone groups. In addition, injection site tolerability was said to be good, with investigators rating injection site pain similar to that with placebo.

\section{Safety in long-term therapy}

Findings from the long-term relapse prevention study showed that weight increase occurred more frequently in patients treated with paliperidone palmitate $(7 \%)$ than placebo $(1 \%)$, as did the blood glucose increase in the paliperidone group (3\%) versus placebo (1\%). ${ }^{20}$ Mean weight, from transition baseline to the double-blind endpoint, increased by $1.9 \mathrm{~kg}$ for paliperidone-treated patients, but remained unchanged for placebo patients. Abnormal weight increases ( $\geq 7 \%$ ) also occurred in twice as many paliperidone patients as placebo patients from both transition and double-blind baselines (see Table 4). There were no clinically relevant changes from transition baseline to the double-blind endpoint in extrapyramidal symptom rating scales and no reports of orthostatic hypotension or ECG changes during the double-blind phase (although ECG changes were seen in the transition and maintenance open-label paliperidone phases). In accordance with other studies, prolactin levels increased for the paliperidone group, again more in women than in men, while levels decreased in the placebo group (see Table 4). No other laboratory parameter changes were noted, and injection site tolerability was similar in all groups. ${ }^{20}$

\section{Other safety data}

The safety and tolerability of initiating treatment with paliperidone palmitate via either deltoid or gluteal injections were investigated in a study comparing the two administration routes. ${ }^{28}$ This crossover trial included 252 stable outpatients randomly assigned 1:1:1 to three dose groups of paliperidone (see Table 4) and two treatment sequences including deltoid muscle injection (13 weeks), followed by gluteal muscle injection (12 weeks), or the reverse. The proportion of patients with injection-site pain appeared to be higher after deltoid administration compared with gluteal administration (41\% deltoid, 26\% gluteus), based on the $90 \% \mathrm{CI}$ of investigator evaluations of the presence of local symptoms at the injection site. The overall incidence of TEAEs did not differ significantly between deltoid injections (period $1=64 \%$, period $2=51 \%$ ) and gluteal injections (period $1=63 \%$, period $2=46 \%$ ), and there was no dose-dependent increase in the incidence of TEAEs. Evaluation of pain by patients revealed slightly more intense pain following deltoid injections compared with gluteal injections for the $78 \mathrm{mg}$ and $117 \mathrm{mg}$ doses of paliperidone, but no difference was detected for the 156 $\mathrm{mg}$ dose. There were no clinically significant changes in extrapyramidal symptom rating scales regardless of the injection site or the dose. ${ }^{28}$

\section{Safety compared with active comparator}

In the two noninferiority studies of paliperidone palmitate and RLAI, the overall rates of TEAEs were found to be similar between the two groups. In the first study, rates of TEAEs were $76 \%$ in the paliperidone group and $79 \%$ in the RLAI group, ${ }^{22}$ whereas in the second study, rates of TEAEs were $57.9 \%$ in the paliperidone group and $52.8 \%$ in the RLAI group. ${ }^{23}$ Therefore, neither drug can be associated with a higher incidence of adverse effects based on these results. In both studies, the incidence of extrapyramidal symptoms was similar in both groups, with the exception of hyperkinesias which was less common in the paliperidone group than in the RLAI group in the first study ( $6 \%$ versus $10 \%$, respectively). ${ }^{22}$ With regard to weight changes, weight actually decreased in the paliperidone palmitate group in the first study compared with RLAI (which caused a slight weight increase), whereas in the second study, mean body weight increases were similar at the endpoint between the two treatment groups (see Table 4). In addition, in the second study, there were no clinically relevant changes in vital signs or ECG, and the incidence of glucose-related TEAEs, as well as investigator assessments of the injection site, were similar in both treatment groups. ${ }^{23}$ Overall, it appears that both paliperidone palmitate and RLAI have comparable adverse effect profiles. However, the second study only lasted 13 weeks, and so long-term comparisons cannot be made. In addition, both studies are currently only available in poster format, thus not allowing for a thorough evaluation of the data. 
Table 5 Adverse effects of paliperidone compared to other antipsychotics

\begin{tabular}{|c|c|c|c|c|c|c|c|c|}
\hline Drug & $\begin{array}{l}\mathrm{QT}_{\mathrm{c}} \\
\text { prolongation }\end{array}$ & Hypotension & Sedation & $\begin{array}{l}\text { Weight } \\
\text { gain }\end{array}$ & $\begin{array}{l}\text { Metabolic } \\
\text { syndrome }\end{array}$ & $\begin{array}{l}\text { Extrapyramidal } \\
\text { symptoms }\end{array}$ & Anticholinergic & $\begin{array}{l}\text { Prolactin } \\
\text { elevation }\end{array}$ \\
\hline Amisulpride & + & - & - & - & + & + & - & +++ \\
\hline Aripiprazole & - & - & - & $+1-$ & $+1-$ & $+1-$ & - & - \\
\hline Asenapine & + & - & + & - & - & + & - & $+1-$ \\
\hline Chlorpromazine & ++ & +++ & +++ & ++ & ++ & ++ & ++ & +++ \\
\hline Clozapine & + & +++ & +++ & +++ & +++ & - & +++ & - \\
\hline Haloperidol & +++ & + & + & + & + & +++ & + & +++ \\
\hline Olanzapine & + & + & ++ & +++ & +++ & $+1-$ & + & + \\
\hline Paliperidone & $-1+$ & ++ & + & ++ & ++ & + & + & +++ \\
\hline Quetiapine & ++ & ++ & ++ & ++ & ++ & - & + & - \\
\hline Risperidone & + & ++ & + & ++ & ++ & + & + & +++ \\
\hline Sulpiride & + & - & - & + & + & + & - & +++ \\
\hline
\end{tabular}

Abbreviations: +++ , high incidence/severity; ++, moderate incidence/severity; +, low incidence/severity; -, very low incidence/severity. Adapted from The Maudsley Prescribing Guidelines 10th Edition. ${ }^{30}$

\section{Summary of safety data}

In summary, paliperidone is relatively well tolerated but, like many other antipsychotics, and as expected from its pharmacological profile, it can cause weight gain and an increase in prolactin levels. Whether weight gain is dose-related or not is still debatable based on the current evidence. However, the rise in prolactin has been shown to be greater with higher doses. In all studies, there were no clinically relevant changes in vital signs, ECG recordings, or other clinical laboratory parameters, and local injection site tolerability was reported to be good. The majority of currently available trials are shortterm, therefore additional longer trials are required in order to assess paliperidone palmitate's long-term safety profile, in particular with regard to changes in metabolic parameters because these may not be picked up in short-term studies. Paliperidone injection and RLAI were found to have comparable adverse effect profiles. Table 5 compares the adverse effects of paliperidone with other antipsychotic agents.

\section{Discussion}

Paliperidone palmitate has been shown to be effective in reducing PANSS total scores in both acute and maintenance treatment of schizophrenia. Improvements in PANSS total scores observed in the majority of studies were greater with higher doses of paliperidone, suggesting a dose-response relationship. Paliperidone injection is generally well tolerated but can cause weight gain and dose-related raised prolactin levels. In two noninferiority studies comparing paliperidone with RLAI, paliperidone injection only proved to be noninferior to RLAI in one study. Paliperidone and RLAI were shown to have comparable adverse effects. Additional long-term trials comparing paliperidone palmitate's efficacy and safety with active comparators are required. The fact that some of the current data for paliperidone injection are only available as poster presentations is an important limitation for its evaluation.

\section{Conclusion}

Given the importance of treatment adherence in schizophrenia, and taking into consideration the compliance problems that often accompany the illness, long-acting antipsychotic injections are a valuable form of therapy. Paliperidone palmitate once-monthly injections may be a useful alternative in a currently limited market. The recommended dosage regimen is $234 \mathrm{mg}$ on day 1 followed by $156 \mathrm{mg}$ a week later, both administered in the deltoid muscle. The recommended maintenance dose is $117 \mathrm{mg}$ monthly, which may be adjusted, based on efficacy and tolerability, within a 39-234 mg range, administered in either the deltoid or gluteal muscle. Paliperidone palmitate has some advantages over available agents, including a faster onset of action than RLAI and the absence of a requirement for oral supplementation at the start of therapy. Therefore, it may be a suitable option in patients who refuse oral treatment. In addition, it is available in a wider variety of strengths than RLAI, allowing for a more specialized and patient-specific dose titration regimen. Since paliperidone can be given either in the deltoid or gluteal muscle after initiation has been established, this improves flexibility of administration. It also has the added advantage of not requiring refrigeration for safe storage. Furthermore, unlike with olanzapine pamoate, "post-injection syndrome" was not reported during the clinical trials with paliperidone, which makes it a suitable agent when a postinjection observation period is not practical.

\section{Disclosure}

The author reports no conflict of interest in this work. 


\section{References}

1. Nasrallah HA. The case for long-acting antipsychotic agents in the post-CATIE era. Acta Psychiatr Scand. 2007;115(4):260-267.

2. Taylor DM, Young C, Patel MX. Prospective 6-month follow-up of patients prescribed risperidone long-acting injection: Factors predicting favourable outcome. Int J Neuropsychopharmacol. 2006;9(6): 685-694.

3. Eli Lilly and Company Limited. Summary of Product Characteristics. Zypadhera $210 \mathrm{mg}, 300 \mathrm{mg}$, and $405 \mathrm{mg}$, powder and solvent for prolonged release suspension for injection. 2009. Available at: http:// emc.medicines.org.uk/ Accessed on Jul 14, 2010.

4. Bishara D, Taylor D. Upcoming agents for the treatment of schizophrenia. Mechanism of action, efficacy and tolerability. Drugs. 2008; 68(16):2269-2296.

5. Nasrallah HA. Atypical antipsychotic-induced metabolic side effects: Insights from receptor-binding profiles. Mol Psychiatry. 2008;13(1):27-35.

6. Haddad PM. Antipsychotics and diabetes: Review of non-prospective data. Br J Psychiatry Suppl. 2004;47:S80-S86.

7. Taylor DM, McAskill R. Atypical antipsychotics and weight gain - a systematic review. Acta Psychiatr Scand. 2000;101(6):416-432.

8. Leysen JE, Janssen PM, Megens AA, Schotte A. Risperidone: A novel antipsychotic with balanced serotonin-dopamine antagonism, receptor occupancy profile, and pharmacologic activity. J Clin Psychiatry. 1994; 55 Suppl:5-12.

9. Schotte A, Janssen PF, Gommeren W, et al. Risperidone compared with new and reference antipsychotic drugs: In vitro and in vivo receptor binding. Psychopharmacology (Berl). 1996;124(1-2):57-73.

10. van Beijsterveldt LE, Geerts RJ, Leysen JE, et al. Regional brain distribution of risperidone and its active metabolite 9-hydroxy-risperidone in the rat. Psychopharmacology (Berl). 1994;114(1):53-62.

11. Cleton A, Rossenu S, Crauwels H, et al. Assessment of the dose proportionality of paliperidone palmitate 25, 50, 100 and $150 \mathrm{mg}$ EG. A new long-acting injectable antipsychotic, following administration in the deltoid or gluteal muscles. Poster presented at American Society for Clinical Pharmacology and Therapeutics. Orlando, FL, 2008 Apr 2-5.

12. Cleton A, Rossenu S, Hough D, et al. Evaluation of the pharmacokinetic profile of deltoid versus gluteal intramuscular injections of paliperidone palmitate in patients with schizophrenia. Poster presented at the American Society for Pharmacology and Therapeutics. Orlando, FL, 2008 Apr 2-5.

13. Janssen. Once-monthly Invega Sustenna: Paliperidone palmitate extended-release injectable suspension. 2009. Available at: http:// www.invegasustenna.com/invegasustenna/assets/hcp/01PM09110.pdf. Accessed on Jul 14, 2010.

14. Kramer M, Litman R, Hough D, et al. Paliperidone palmitate, a potential long-acting treatment for patients with schizophrenia. Results of a randomized, double-blind, placebo-controlled efficacy and safety study. Int J Neuropsychopharmacol. 2010;13(5):635-647.

15. Samtani MN, Vermeulen A, Stuyckens K. Population pharmacokinetics of intramuscular paliperidone palmitate in patients with schizophrenia: A novel once-monthly, long-acting formulation of an atypical antipsychotic. Clin Pharmacokinet. 2009;48(9):585-600.

16. Sedky K, Nazir R, Lindenmayer JP, Lippman S. Paliperidone palmitate: Once monthly treatment option for schizophrenia. Current Psychiatry Online. 2010;9(3):48-50.
17. Gopal S, Hough DW, Xu H, et al. Efficacy and safety of paliperidone palmitate in adult patients with acutely symptomatic schizophrenia: A randomized, double-blind, placebo-controlled, dose-response study. Int Clin Psychopharmacol. 2010 Apr 10. [Epub ahead of print].

18. Pandina GJ, Lindenmayer JP, Lull J, et al. A randomized, placebocontrolled study to assess the efficacy and safety of 3 doses of paliperidone palmitate in adults with acutely exacerbated schizophrenia. J Clin Psychopharmacol. 2010;30(3):235-244.

19. Nasrallah HA, Gopal S, Gassmann-Mayer C, et al. Efficacy and safety of three doses of paliperidone palmitate, an investigational longacting injectable antipsychotic in schizophrenia. Poster presented at the Institute on Psychiatric Services Annual Meeting, Chicago, IL, 2008 Oct $2-5$

20. Hough D, Gopal S, Vijapurkar U, Lim P, Morozova M, Eerdekens M. Paliperidone palmitate maintenance treatment in delaying the timeto-relapse in patients with schizophrenia: A randomized, double-blind, placebo-controlled study. Schizophr Res. 2010;116(2-3):107-117.

21. Gopal S, Vijapurkar U, Lim P, Morozova M, Eerdekens, Hough D. A 52-week open-label study of the safety and tolerability of paliperidone palmitate in patients with schizophrenia. J Psychopharmacol. OnlineFirst. July 8, 2010:doi:10.1177/0269881110372817.

22. Fleischhacker WW, Gopal S, Samtani M, et al. Optimization of the dosing strategy for the long-acting injectable antipsychotic paliperidone palmitate: Results of two randomized double-blind studies and population pharmacokinetic simulations. Poster presented at the American Society for Pharmacology and Therapeutics. Scottsdale, AZ, 2008 Dec 7-11.

23. Pandina G, Lane R, Gopal S, et al. A randomized, double-blind, comparative study of flexible doses of paliperidone palmitate and risperidone long-acting therapy in patients with schizophrenia. Poster presented at the 48th American College of Neuropsychopharmacology. Hollywood, FL, 2009 Dec 6-10.

24. Kay SR, Fiszbein A, Opler LA. The positive and negative syndrome scale (PANSS) for schizophrenia. Schizophr Bull. 1987;13(2):261-276.

25. Haro JM, Kamath SA, Ochoa S, et al. The Clinical Global ImpressionSchizophrenia scale: A simple instrument to measure the diversity of symptoms present in schizophrenia. Acta Psychiatr Scand Suppl. 2003;(416):16-23.

26. Patrick DL, Adriaenseen I, Morosini PL, Gagnon D, Rothman M. Reliability, validity and sensitivity to change of the Personal and Social Performance scale in patients with acute schizophrenia. Poster presented at Collegium Internationale Neuro-psychopharmacologicum. Chicago, IL, 2006 Jul 9-13.

27. Citrome L. Paliperidone palmitate - review of the efficacy, safety and cost of a new second-generation depot antipsychotic medication. Int J Clin Pract. 2010;64(2):216-239.

28. Hough D, Lindenmayer JP, Gopal S, et al. Safety and tolerability of deltoid and gluteal injections of paliperidone palmitate in schizophrenia. Prog Neuropsychopharmacol Biol Psychiatry. 2009;33(6):1022-1031.

29. Coppola D, Liu Y, Gopal S, et al. Long-term safety, tolerability and pharmacokinetics of paliperidone palmitate $234 \mathrm{mg}$ ( $150 \mathrm{mg}$ eq.), the highest marketed dose: A one-year open-label study in patients with schizophrenia. Poster presented at the American Society for Pharmacology and Therapeutics. Atlanta, GA, 2010 Mar 17-30.

30. Taylor D, Paton C, Kapur S. The Maudsley Prescribing Guidelines 10th Edition. London: Informa Healthcare; 2009.
Neuropsychiatric Disease and Treatment

\section{Publish your work in this journal}

Neuropsychiatric Disease and Treatment is an international, peerreviewed journal of clinical therapeutics and pharmacology focusing on concise rapid reporting of clinical or pre-clinical studies on a range of neuropsychiatric and neurological disorders. This journal is indexed on PubMed Central, the 'PsycINFO' database and CAS, and is the official

\section{Dovepress}

journal of The International Neuropsychiatric Association (INA). The manuscript management system is completely online and includes a very quick and fair peer-review system, which is all easy to use. Visit $\mathrm{http}: / / \mathrm{www}$.dovepress.com/testimonials.php to read real quotes from published authors. 